Anuario de

Derechos Humanos 2005 


\section{La Democracia y el Mal Menor*}

\author{
Michael Ignatieff**
}

El día señalado, la muchedumbre desarmada de la juventud gótica fue reunida con todo cuidado en la plaza del foro; las calles y avenidas fueron copadas por tropas romanas y los techos de las casas estaban cubiertos de arqueros y tiradores armados con hondas. A la misma hora, en todas las ciudades del Oriente, se dio la señal de ejecutar una matanza indiscriminada con lo que las provincias de Asia fueron liberadas, mediante la cruel prudencia de Julio, de un enemigo interno, quien en un plazo de pocos meses podría haber llevado el fuego y la espada desde el Helesponto al Éufrates. La consideración imperiosa de la seguridad pública indudablemente puede autorizar la violación de toda ley positiva. Hasta dónde puede operar aquella consideración o cualquier otra para violar las obligaciones naturales de humanidad y justicia es una doctrina respecto de la cual todavía prefiero permanecer en la ignorancia.

EDWARD GIBBON,

Decadencia y caída del Imperio Romano (1/76) 2.36 (versión libre del traductor)

I

¿Q ué males menores puede cometer una sociedad cuando cree que enfrenta el mal mayor de su propia destrucción? Esta es una de las preguntas más antiguas en política y una de las más difíciles de responder. El viejo refrán romano (la seguridad del pueblo es la ley primera) fija pocos límites a las exigencias de la seguridad por sobre la libertad. En nombre de la seguridad del pueblo, la República Romana estaba preparada a sacrificar las demás leyes. Porque, ¿qué leyes sobrevivirían si Roma misma perecía? La suspensión de las libertades civiles, la detención de los extranjeros, el asesinato en secreto de los enemigos: todo se podía permitir, como último recurso, si la existencia del Estado estaba en peligro. Pero si en ocasiones la ley debe hacer concesiones frente a la necesidad, ¿es necesario que la ética también se someta? ¿No hay límite moral a lo que puede hacer una república cuando su existencia está amenazada? Cuando Edward Gibbon relató cómo los romanos masacraron a los extranjeros indefensos en sus ciudades orientales en el año 395 d.c., como advertencia preventiva a los bárbaros que se reunían en masa en las puertas de su imperio, se negó a considerar si las acciones requeridas por la necesidad política podían seguir siendo un anatema para los principios morales. Esta es una pregunta que no sólo debe plantearse, sino que es preciso responderla.

Si la sociedad atacada el 11 de septiembre de 2001 hubiera sido una tiranía, quizás estas antiguas preguntas no habrían sido pertinentes, porque una tiranía se permite cualquier cosa. Pero la nación atacada esa mañana
Título original:

"Democracy and the Lesser Evil". Capítulo 1 del libro The Lesser Evil. Political Ethics in an Age of Terror. The Gifford Lectures. Publicado por Princeton University Press, USA (2004), pp. 1-24. (C) Michael Ignatieff.

* Traducido al castellano por el Centro de Derechos Humanos, Facultad de Derecho, Universidad de Chile, y reproducido con la autorización expresa de Michael Ignatieff, titular del derecho de autor.

** Director del Carr Center for Human Rights Policy, Harvard University. 
** Nota del editor: el autor utiliza a lo largo de este texto el adjetivo inglés "adversarial" para referirse a una revisión, control o debate sobre decisiones de la autoridad efectuado de modo independiente y crítico por parte de otros poderes del Estado o por la opinión pública. Hemos preferido emplear en castellano el adjetivo homónimo "adversarial", aunque estrictamente se trata de un neologismo, en razón de que el uso dado por el autor y otros autores puede estarle dando una connotación de expresión técnica que la traducción "confrontacional" no reflejaría adecuadamente.

1 Cass R. Sunstein, Designing Democracy: What Constitutions Do (Nueva York: Oxford University Press, 2001), 6-8, 13-47. Dennis Thompson y Amy Gutmann, Democracy and Disagreement (Cambridge: Harvard University Press, Belknap Press, 1996), 41-49. luminosa era una democracia liberal, un orden constitucional que establece límites al uso de la fuerza por parte de cualquier gobierno. Las constituciones democráticas permiten alguna suspensión de derechos en estados de emergencia. En consecuencia, los derechos no siempre son una "carta de triunfo". Pero tampoco lo es la necesidad. Incluso en momentos de peligro real, las autoridades políticas deben demostrar que la restricción de derechos es justificada. Fundamentar tal restricción exige que el gobierno someta sus medidas a la revisión adversarial** por parte del poder legislativo, los tribunales y los medios de comunicación libres. Un gobierno que busca responder a un ataque o un peligro esperado está obligado a fundamentar las medidas extraordinarias que juzga necesarias ante el poder legislativo, a argumentar a favor de las mismas mediante razones que podrían convencer a personas razonables y a modificar las medidas frente a las críticas. Incluso una vez aprobadas las medidas extraordinarias por el poder legislativo, éstas pueden ser revisadas por los tribunales.

El primer desafío que una emergencia terrorista plantea a una democracia es este sistema de justificación adversarial. La maquinaria de la deliberación legislativa y la revisión judicial se mueven lentamente. Las emergencias requieren de acción rápida. En consecuencia, exigen el ejercicio de las prerrogativas del Poder Ejecutivo. Los presidentes y los primeros ministros deben tomar medidas primero y luego hacer preguntas. Pero el exceso de tales prerrogativas puede ser perjudicial para la democracia en sí.

En casos de emergencia, no queda otra alternativa que confiar en nuestros líderes y dejarlos actuar rápidamente cuando nuestras vidas corren peligro, pero no sería correcto confiar en ellos para que decidan la cuestión de mayor alcance de cómo equilibrar la libertad y la seguridad a largo plazo. Para estos dilemas mayores, debemos confiar en la deliberación democrática a través de nuestras instituciones. La justificación adversarial es una respuesta institucional, desarrollada a través de los siglos, frente a la dificultad inherente en tomar decisiones públicas apropiadas precisamente sobre este tipo de conflicto de valores ${ }^{1}$. Es altamente probable que los ciudadanos no estén de acuerdo acerca de hasta dónde tiene derecho a llegar el gobierno en una emergencia específica. Debido a que discrepamos profundamente respecto de estos asuntos, las instituciones democráticas proporcionan una resolución, mediante un mecanismo de equilibrio de poderes, para garantizar que la respuesta de ningún gobierno pueda llevarnos directamente tanto a la anarquía como a la tiranía.

Frente a una emergencia terrorista, no estamos de acuerdo, en primer lugar, acerca de lo sucedido: principalmente, el tipo y grado de riesgo que representa la amenaza terrorista. Sería más fácil si estos hechos fueran evidentes, pero rara vez lo son. La seguridad pública requiere realizar extrapolaciones acerca de futuras amenazas a partir de hechos discutibles respecto de las amenazas actuales. Lo que es peor aún: los hechos nunca se presentan ante el público simplemente como propuestas neutras 
susceptibles de ser examinadas en forma desapasionada. Nos llegan junto con una evaluación. A menudo se adaptan los hechos para justificar el curso de acción que se está proponiendo. Quienes favorecen medidas represivas habitualmente representan el riesgo como un hecho de alcance mayor; en cambio, los que se oponen a estas medidas tienden a minimizarlo. Los desacuerdos no terminan ahí. Incluso cuando estamos de acuerdo respecto de los hechos, podemos seguir estando en desacuerdo acerca de si los riesgos justifican las restricciones a la libertad.

Estos desacuerdos se extienden hasta el significado mismo de la democracia. Para la mayoría de los estadounidenses, la democracia sencillamente significa lo que señaló Abraham Lincoln: el gobierno del pueblo, por el pueblo, para el pueblo. Desde este punto de vista, la democracia es sinónimo de gobierno de la mayoría. La soberanía popular, por medio de representantes electos, debe ser el árbitro final de lo que le está permitido al gobierno cuando intenta defender nuestras libertades y nuestras vidas. Las democracias efectivamente cuentan con declaraciones de los derechos de los ciudadanos, pero éstas existen para servir a vitales intereses mayoritarios. Cuando el poder ejecutivo suspende los derechos, por ejemplo, lo hace en beneficio de la mayoría de los ciudadanos. Los intereses públicos que estos derechos defienden son definidos por los representantes elegidos por el pueblo y los tribunales deben interpretar lo que significan respetando lo que el poder legislativo y el pueblo dicen que significan ${ }^{2}$. Defender el derecho de un individuo, por ejemplo, a la libertad de asociación en tiempos de tranquilidad, sirve para proteger la libertad de todos. Pero proteger a la misma persona en tiempos de emergencia puede ser perjudicial para todos. Una emergencia terrorista es precisamente una situación en que el hecho de permitir una libertad individual (para planificar, complotar, evadir la detección) puede constituir una amenaza para un interés esencial de la mayoría. Una democracia no tiene propósito más importante que la protección de sus miembros y los derechos existen para proteger ese propósito. Como ha señalado el Presidente de la Corte Suprema de Estados Unidos, las libertades civiles significan la libertad de un ciudadano y no la libertad en abstracto de un individuo en estado natural ${ }^{3}$. Dicha libertad, por tanto, debe depender de la supervivencia del gobierno y debe estar subordinada a su preservación.

Lo que impide que un sistema de esta naturaleza sea víctima de la tiranía de la mayoría es el mecanismo de equilibrio de poderes y, en términos más generales, el proceso democrático de justificación adversarial en sí. Si bien la injusticia siempre se puede justificar si uno solamente la tiene que defender ante uno mismo, resulta un poco más difícil cuando hay que justificarla ante otras instituciones democráticas, como los tribunales, el poder legislativo o los medios de comunicación libres. En consecuencia, es posible que los presidentes y primeros ministros no consideren que una medida restrictiva es errónea, pero si saben que dicha medida tendrá que ser aprobada por los tribunales y el poder legislativo, lo pensarán dos veces.
2 John Hart Ely, Democracy and Distrust: $A$ Theory of Judicial Review (Cambridge: Harvard University Press, 1980), 4: "he ahí, la función principal, que es al mismo tiempo el problema medular de la revisión judicial: una entidad que no es electa ni tiene por otra vía responsabilidad política significativa, le está señalando a los representantes electos del pueblo que no pueden gobernar a su antojo... En Estados Unidos esta es una acusación que importa".

3 William H. Rehnquist, All the Laws but One: Civil Liberties in Wartime (Nueva York: Knopf, 1998), 222. 
4 The Federalist N ${ }^{\circ} 51$ http:/ /memory.loc.gov/const/ fed/fedpapers.htm/ (con acceso el 4 de diciembre de 2003).

5 Véase la descripción de cómo una Corte Suprema busca equilibrar los dos significados en tiempos de terrorismo, en A. Barak "A Judge on Judging: The Role of a Supreme Court in a Democracy", Harvard Law Review 116 $N^{\circ} 1$ (noviembre 2002): 16-162 y particularmente 36-46 y 148-60.

6 Ronald Dworkin, "Philosophy and Monica Lewinsky", New York Review of Books, 9 de marzo de 2000: Ronald Dworkin, "Posner's Charges: What I Actually Said" (2000), http:// www.nyu.edu/gsas/dept/ philo/faculty/dworkin/ (con acceso el 4 de diciembre de 2003). Ronald Dworkin, Freedom's Law: The Moral Reading of the American Constitution (Cambridge: Harvard University Press, 1996), vs. Richard Posner The Problematics of Moral and Legal Theory (Cambridge: Harvard University Press, Belknap Press, 1999).
Además del mecanismo constitucional de equilibrio de poderes, existe también el contrapeso democrático de los intereses sociales, religiosos y políticos que compiten entre sí en la nación en general. Una de las versiones más lúcidas de este argumento aparece en Federalist $\mathrm{N}^{\mathrm{o}}$ 51, en el que, al analizar el sistema de equilibrio entre el poder federal y estadual, los autores señalan que, si bien toda la autoridad en Estados Unidos se deriva del poder de la mayoría,

"Ia sociedad misma estará dividida en tantas partes, intereses y clases de ciudadanos, que los derechos de los individuos, o los de la minoría, correrán poco riesgo de combinaciones interesadas de la mayoría. En un gobierno libre, la protección de los derechos civiles debe ser la misma que la de los derechos religiosos. Se trata, por una parte, de la variedad de intereses y sectas; y se puede presuponer que esto depende de la extensión del país y del número de personas bajo el mismo gobierno" ${ }^{\prime \prime 4}$.

En contra de esta visión pragmática existe una visión moral de la democracia que sostiene que es algo más que el gobierno de la mayoría sometido a la disciplina del mecanismo de equilibrio de poderes. Es también un orden de derechos que pone límites al poder de la comunidad respecto de las personas. Estos límites no existen sólo por razones prudenciales, para impedir que el gobierno trate sin miramientos a los individuos. Los derechos también existen para expresar la idea de que los individuos tienen importancia intrínseca. Las democracias no sólo sirven a los intereses mayoritarios sino que otorgan respeto intrínseco a los individuos. Este respeto se expresa en la forma de derechos que garantizan ciertas libertades. Las libertades tienen importancia, a su vez, porque constituyen una condición previa para vivir con dignidad. En este caso la dignidad se refiere simplemente al derecho de vivir la propia vida de la mejor manera posible, dentro de los límites establecidos por la ley, y de tener derecho a voz, por pequeña que sea la participación, en cuanto a cómo se manejan los asuntos públicos. Dicho de otro modo, el gobierno para el pueblo es algo más que el gobierno para la felicidad y la seguridad de la mayoría. La limitación esencial del gobierno democrático es que, en primer lugar, debe servir a los intereses mayoritarios sin sacrificar la libertad y la dignidad de los individuos que forman la comunidad política y que, en ocasiones, pueden oponerse a la forma en que se los gobierna. Los derechos ciertamente tienen su origen en la soberanía de los pueblos, pero la gente (y sus representantes) deben orientarse hacia los intereses mayoritarios respetando las limitaciones que imponen los derechos.

Aharon Barak, presidente de la Corte Suprema de Israel, describe estos dos conceptos de democracia como "formal" y "sustantivo" ${ }^{5}$. Otros académicos han contrastado una lectura "pragmática" de la Constitución de los Estados Unidos con una lectura "moral" ${ }^{6}$. En épocas normales, estos dos significados de la democracia (una que recalca la soberanía popular y la otra que hace hincapié en los derechos; una que privilegia los intereses colectivos y la otra que favorece la dignidad individual), son interdependientes. No se puede 
tener una democracia sin derechos y los derechos no podrán estar seguros a menos que se cuente con una democracia. Pero en emergencias terroristas, la relación entre ellas se rompe. Lo que hace que la seguridad aparentemente prevalezca sobre la libertad en emergencias terroristas es la idea, indudablemente cierta, de que la libertad de la mayoría depende completamente de su seguridad. Un pueblo que vive atemorizado no es libre. En consecuencia, la seguridad de la mayoría tiene una reivindicación imperativa. En este sentido, los derechos son expedientes políticos establecidos por una mayoría para su defensa y, por lo tanto, tal mayoría tiene libertad de coartarlos, cuando la necesidad lo impone. Por otra parte, aquellos que defienden una definición de la democracia basada en los derechos argumentarán que los derechos pierden toda su eficacia, no solamente para las personas que están en situación de riesgo sino que también para la mayoría, si son revocables en caso de necesidad.

Ambas partes recurren, entonces, a la historia para revindicar sus posiciones. Aquellos que conciben la democracia primordialmente en términos de interés de la mayoría, apuntan a las reiteradas restricciones a la libertad en las emergencias nacionales que se han producido anteriormente, desde la suspensión del habeas corpus por parte de Lincoln durante la Guerra Civil hasta la detención de extranjeros ilegales después del 11 de septiembre, y afirman que las democracias sobreviven, en parte, porque no dejan que los derechos entorpezcan la aplicación de medidas enérgicas. Por otra parte, las medidas enérgicas no impiden que los derechos rijan nuevamente en tiempos de seguridad. Las medidas provisionales son precisamente eso y no necesariamente tienen que dañar en forma permanente el tejido constitucional de la democracia. Quienes colocan los derechos en primer lugar responderán que sí, la democracia sobrevive, pero que la violación de los derechos compromete innecesariamente la obligación que la democracia tiene con la dignidad y la libertad. La detención de los japoneses-estadounidenses durante la Segunda Guerra Mundial sería un ejemplo de tiranía mayoritaria y uso indebido de una prerrogativa del poder ejecutivo, motivado por el temor y el prejuicio racial ${ }^{7}$. Una parte de los que debaten se preocupa porque la excesiva preocupación por los derechos dejará a la democracia atada de manos, mientras que la otra parte insiste que si se restringen los derechos, aunque sean solamente aquellos de algunos individuos, la democracia traiciona su propia identidad.

Los partidarios de las libertades civiles piensan que éstas definen lo que es la democracia. Pero el apoyo público recurrentemente débil y superficial por las posiciones en pro de las libertades civiles sugiere que muchos estadounidenses están en desacuerdo. Estos creen que el interés de la mayoría debería predominar por encima de las libertades civiles de quienes se sospecha que son terroristas ${ }^{8}$. Para estos demócratas, los derechos son límites prudenciales a la acción del gobierno, revocables en tiempos de peligro; los partidarios de las
7 Peter Irons, Justice at War (Nueva York: Oxford University Press, 1983) 913, 57-64. David Cole "An Ounce of Detention", American Prospect, 9 de septiembre de 2003.

8 Resultados de la Encuesta USA Today/CNN Gallup (agosto de 2003), http:// www. lifeandliberty.gov/ subs/s_people.htm (con acceso el 4 de diciembre de 2003). En respuesta a la pregunta "En su opinión, ¿cree usted que el gobierno del Presidente Bush se ha excedido, ha estado más bien en lo correcto o no ha restringido las libertades civiles suficientemente en la lucha contra el terrorismo?", entre un 55 y un $60 \%$ de los encuestados respondieron "ha estado más bien en lo correcto", cifras que permanecieron relativamente estables desde junio de 2002. El $48 \%$ de la muestra opina que la Ley Patriótica (Patriot Act) logra un equilibrio entre libertad $y$ seguridad "relativamente adecuado". 
9 David Cole, Enemy Aliens, (Nueva York: New Press, 2003).

10 Sobre la idea de un enemigo de la raza humana, véase la discusión que aparece en el libro de Hannah Arendt, Eichmann in Jerusalem: A report on the Banality of Evil (Nueva York: Viking, 1963).

11 Ronald Dworkin, "Terror and Attack on Civil Liberties", New York Review of Books, 6 de noviembre de 2003. libertades civiles estiman que son compromisos fundacionales frente a la dignidad individual que debieran limitar igualmente la acción gubernamental tanto en tiempos de seguridad como de peligro. Para unos, lo que importa, en términos esenciales, es que subsistan las democracias. Para otros, lo que importa más es que las democracias subsistan sin traicionar lo que representan.

Hay un desacuerdo adicional en cuanto a si un país que enfrenta una emergencia terrorista debe basar su política pública exclusivamente en su Constitución y sus leyes o si está obligado a tomar en consideración la opinión de los demás Estados y lo establecido por los acuerdos y convenciones internacionales. Algunos sostienen que los compromisos de la democracia con la dignidad se limitan a sus propios ciudadanos y no se extienden a sus enemigos. Otros señalan que una democracia no es una isla moral autosuficiente. En consecuencia, como han señalado muchos académicos, la Constitución Política de Estados Unidos extiende su protección a "personas" y no solamente a ciudadanos ${ }^{9}$. Por lo tanto, los extranjeros tienen derechos bajo las leyes de Estados Unidos, como también, evidentemente, bajo las convenciones internacionales de las que Estados Unidos es signatario. Los combatientes enemigos tienen derechos en virtud de las Convenciones de Ginebra e incluso los terroristas conservan sus derechos humanos dado que éstos son inherentes al hecho de ser humano y por lo tanto irrevocables. Otros piensan que este enfoque valora más la coherencia que la justicia. La justicia, para las víctimas de las atrocidades terroristas, requiere que los terroristas sean tratados como "enemigos de la raza humana" y perseguidos sin consideración alguna por sus derechos humanos ${ }^{10}$.

Cuando los ciudadanos de una democracia insisten que lo más importante en una emergencia terrorista es la seguridad de la mayoría, generalmente están diciendo que los derechos son, en el mejor de los casos, una restricción lateral y, en el peor de los casos, un impedimento molesto frente a una acción decisiva y vigorosa. Quienes piensan de este modo probablemente piensan también que los acuerdos internacionales, tales como las Convenciones de Ginebra o la Convención contra la Tortura, no debieran plantear limitaciones a lo que puede hacer Estados Unidos en una guerra contra el terrorismo. Dado que la amenaza va dirigida principalmente en contra de Estados Unidos, el país debe responder de acuerdo con su propio sistema de leyes y no de acuerdo con las normas de los demás. Sin embargo, el hecho de adoptar esta posición equivale también a suponer que la vida de los propios ciudadanos vale más que la vida de la gente de otros países. Como ha señalado Ronald Dworkin, ello es equivalente a basar la política en la premisa de que los estadounidenses están primero $^{11}$. Los que no concuerdan con esta idea generalmente están comprometidos con la noción de que los compromisos éticos de una democracia son universales y son válidos tanto para sus ciudadanos como para sus enemigos. 
Estos debates también tienen que ver con el hecho de que algunas medidas simplemente son incorrectas. Los consecuencialistas afirman que las medidas cuyo objeto es salvar vidas y conservar la seguridad de los ciudadanos no pueden ser incorrectas si efectivamente logran hacerlo. Lo serían solamente si no funcionan, es decir, si producen una cadena de daños adicionales; por ejemplo, más ataques terroristas. La mayoría de los partidarios de las libertades civiles creen que algunas acciones siguen siendo incorrectas aunque funcionen. De este modo, torturar a una persona para que revele acciones terroristas es errado a pesar de que se logre extraer información útil y, en consecuencia, ninguna democracia debiera involucrarse jamás en actividades de tortura. Hay una tercera postura que está entre las otras dos, que sostiene que las consecuencias pueden ser tan importantes al salvar a miles de personas de los ataques terroristas que bien podría valer la pena someter a un individuo a un interrogatorio sin tregua, aunque sin violencia física, para extraer información esencial. Pero este tipo de interrogatorio, que llevaría a los sospechosos a los límites de su tolerancia psicológica, seguiría siendo una violación de su dignidad. Sería un mal menor comparado con permitir que miles de personas murieran, pero la necesidad de hacerlo no significaría que no es incorrecto.

Esta tercera postura, que corresponde al título de este libro, afirma que la necesidad nos puede llevar a tomar medidas en defensa de la democracia que se apartan de los compromisos fundacionales con la dignidad que son propios de la democracia misma. Si bien no podemos evitar esto, la mejor manera de minimizar los daños es que mentalmente mantengamos una clara distinción entre lo que la necesidad permite justificar y lo que la moral de la dignidad puede justificar y no permitir jamás que las justificaciones de la necesidad (riesgo, amenaza, peligro inminente) desbaraten el carácter moralmente problemático de las medidas necesarias. Justamente porque las medidas son moralmente problemáticas deben ser estrictamente focalizadas, aplicadas al número más pequeño posible de personas, utilizadas como último recurso y sujetas al escrutinio adversarial de un sistema democrático abierto.

La postura del mal menor sostiene que, ante una emergencia terrorista, ni los derechos ni la necesidad debieran ser una "carta de triunfo". La democracia está comprometida tanto con la seguridad de la mayoría como con los derechos del individuo. No se puede permitir que la moralidad de las consecuencias o la moralidad de la dignidad tengan un predominio exclusivo en la toma de decisiones de políticas públicas. Dado que cada uno de estos principios éticos conlleva legítimas exigencias, el marco resultante será complejo, por decir lo menos, y no habrá "cartas de triunfo", ni justificaciones o títulos que ganen todo lo que está sobre la mesa de juego. Lo que funciona no siempre es lo correcto. Lo que es correcto no siempre funciona. Es posible que los derechos tengan que ceder ante la seguridad en algunos casos pero más vale que haya buenas razones y claras restricciones 
para limitar los derechos; de lo contrario, los derechos rápidamente pierden todo su valor. Al mismo tiempo, una Constitución política no es un pacto suicida: los derechos no pueden limitar a un punto tal el ejercicio de la autoridad que tornen imposible toda acción decisiva. Por último, las normas internacionales son importantes. Las naciones no son islas morales: deben cumplir con las normas internacionales, tanto en lo que se refiere a respetar los tratados y las convenciones que han firmado como también, como decía Thomas Jefferson, para mostrar "un decente respeto por las opiniones de la humanidad".

La moralidad del mal menor ha sido diseñada para los escépticos, para gente que acepta que los líderes deben tomar acciones perentorias basadas en información que dista mucho de ser precisa; para quienes piensan que puede ser necesario sacrificar cierto grado de libertad en momentos de peligro; para quienes quieren una política que funcione pero que no están dispuestos a hacer que lo que funcione sea el único criterio para decidir lo que se debe hacer. Este tipo de ética es un acto de equilibrio: se busca lograr una adjudicación entre las afirmaciones de riesgo, dignidad y seguridad de tal forma que realmente se aborden los casos particulares de amenaza. Una ética de equilibrio no puede privilegiar los derechos, la dignidad o la seguridad pública por encima de todo lo demás. Privilegiar un aspecto y excluir los demás, es la jugada que produce el error moral. Todos son principios importantes, todos deben ser sopesados igualmente en la balanza y ninguno debe prevalecer sobre los demás.

Esta es una ética de prudencia en lugar de principios primarios; una que evalúa qué se debe hacer frente a una emergencia con un sesgo conservador en contra de la trangresión de los estándares establecidos sobre debido proceso, igualdad ante la ley y dignidad básica. Un sesgo conservador supone que, ante emergencias terroristas, la primera respuesta suele ser errónea. Las normas del debido proceso que se han asentado a lo largo del tiempo no deben ser descartadas apresuradamente. Estas normas son más que meros procedimientos, anclados en la tradición legal. Reflejan compromisos importantes con la dignidad individual. En concreto, la protección de la ley significa que nadie debe ser detenido en forma indefinida, sin tener acceso a asistencia legal o revisión judicial. Más aún, las personas sólo pueden ser detenidas por lo que han hecho, no por quienes son ni por lo que piensan, profesan o creen. Un principio conservador clave sería que las detenciones a granel y las redadas generales de sospechosos siempre son un error porque violan el principio de la ley en cuanto a la individualidad de la culpa. Es invariablemente incorrecto arrestar o detener gente sobre la base del principio de culpa por asociación, sobre la base de raza, origen étnico o filiación religiosa. Toda política de detención debe estar orientada a aquellos individuos contra quienes se pueda demostrar que existe una causa probable. De acuerdo con estas normas, Estados Unidos no pasó la prueba al detener a casi cinco mil extranjeros, principalmente hombres solteros de origen árabe 
o musulmán, después del 11 de septiembre. No se ha encontrado que ninguno de los detenidos reunía las condiciones necesarias para ser acusados de actos terroristas. En retrospectiva, todo el ejercicio pareciera haber sido tan innecesario como injusto ${ }^{12}$.

Si bien un sesgo conservador nos permitirá discernir la mayoría de las reacciones excesivamente apresuradas ante las emergencias terroristas, puede no ser adecuado cuando estamos ante la necesidad de enfrentar a terroristas que controlan armas de destrucción masiva. Si la amenaza es de magnitud suficiente, quizás sea necesario efectuar detenciones preventivas de los sospechosos, junto con realizar acciones militares o policiales para desarmar, inhabilitar o neutralizar la amenaza. Es poco realista pensar que los compromisos con la dignidad, acompañados de un sesgo conservador en contra de apartarse de las normas legales comprobadas, serán suficientes para hacer frente a cualquier eventualidad en el futuro. Luego de otro ataque terrorista en que se produzcan bajas en cantidad equivalente o mayor a las que se produjeron el 11 de septiembre, gran parte de los miramientos se disiparían. Sin embargo, ni siquiera una situación de necesidad extrema puede pasar por alto los procesos democráticos y la obligación de equilibrar las medidas drásticas con el compromiso básico de ofrecer una plena justificación pública.

Si una guerra contra el terrorismo puede requerir males menores, ¿qué impedirá que lentamente se conviertan en el mal mayor? La única respuesta es la democracia misma. La democracia liberal ha perdurado porque sus instituciones están diseñadas para hacer frente a formas moralmente peligrosas de poder coercitivo. Esto plantea la cuestión de hasta dónde debe llegar el gobierno en el fuego cruzado de la revisión adversarial. Los procedimientos de la revisión adversarial no solamente enfrentan a una rama del gobierno contra la otra, sino que al interior de una misma rama existen y debieran haber equilibrios y contrapesos, cortafuegos que garanticen la independencia de las instituciones que llevan a cabo la revisión al interior de las agencias. Por ejemplo, el General Accounting Office controla los gastos de otras agencias federales del gobierno estadounidense. Una unidad del Departamento de Justicia criticó recientemente la forma en que otra unidad manejó a los detenidos por disposición del Poder Ejecutivo con posterioridad al 11 de septiembre, con lo cual esta última modificó su forma de operar ${ }^{13}$.

En este proceso de revisión adversarial el test de la razón no es el test de la perfección. Los ciudadanos generalmente aceptan las decisiones resultantes, no porque sean las correctas sino porque son razonables y porque la revisión democrática permite un verdadero debate adversarial y abierto de opiniones. Por supuesto, hasta el proceso más abierto puede producir resultados perversos. El Senador Joseph McCarthy acosó y difamó a personas sospechosas de ser simpatizantes comunistas a plena luz de la publicidad y, durante un tiempo, contó con el apoyo de la mayoría. Si bien los procedimientos abiertos son falibles, por lo menos
${ }^{12}$ Cole, Enemy Aliens.

13 U.S. Justice Department Inspector General Report on Administrative Detention (junio de 2003), http:// www.usdoj.gov/oig/ special/03-06/index.htm (con acceso el 4 de diciembre de 2003). 
${ }^{14}$ Robert D. Marcus y Anthony Marcus, eds., "The Army-McCarthy Hearings, 1954" en American History through Court Proceedings and Hearings" vol. 2 (St. James, N.Y.: Brandywine Press, 1998), 136-51.

15 Dennis E. Thompson, Political Ethics and Public Office (Cambridge: Harvard University Press, 1987), 118; también Dennis Thompson, "Democratic Secrecy", Political Science Quarterly 114, № 2 (verano de 1999): 181-93. Véase también US. Senate Final Report of the Select Committee to Study Governmental Operations with Respect to Intelligence Activities (Washington D.C.: U.S. Government Printing Office, 1976), 11-14. generan la posibilidad de corregir los errores. Aunque McCarthy persiguió a gente inocente en procedimientos abiertos, también su caída fue provocada por el mismo tipo de procedimiento ${ }^{14}$. En última instancia, si los procedimientos abiertos no logran producir respuestas que cuenten con el consentimiento de los ciudadanos, son ellos quienes deben obligar a las instituciones, por medio de la crítica pública y los procesos electorales, a producir mejores respuestas. Un aspecto impactante de la democracia es el papel que desempeña la desconfianza en lograr mantener honesto al sistema. El sistema de equilibrio y contrapesos y la separación entre los poderes del Estado supone la posibilidad de deshonestidad o incapacidad en una institución u otra. La seguridad última en una democracia radica en que las decisiones que logran atravesar el filtro de este largo proceso tienen menos posibilidades de ser erróneas que aquellas que se toman, de una vez, en la cumbre.

La guerra librada contra el terrorismo desde el 11 de septiembre causa tensiones a la democracia misma porque, en la mayor parte, se lleva a cabo en forma oculta, utilizando medios que están al borde de la ley y la moralidad. Sin embargo, las democracias han demostrado ser capaces de mantener bajo control el ejercicio secreto del poder. El secreto se puede controlar siempre que "la decisión que impone reserva no sea, en sí misma, secreta" ${ }^{\prime 15}$. El poder legislativo puede realizar audiencias sobre asuntos sensibles de inteligencia a puerta cerrada; los jueces pueden exigir que los fiscales estatales justifiquen que las audiencias se deban realizar en absoluta reserva o que no se entregue determinada información a la parte acusada. Las líneas rojas deben ser claras: jamás se justifica relegar o deportar a un extranjero o a un ciudadano mediante procedimientos realizados en secreto. La publicidad en cualquier proceso en el que esté en juego la libertad humana es sencillamente un factor definitorio de lo que es la democracia. El problema no consiste en definir dónde está la línea roja sino en hacer que se cumpla. Una democracia en la que la mayoría de la gente no vota pero en la que muchos jueces otorgan una deferencia desmedida a las decisiones del poder ejecutivo y en la que el gobierno se niega a permitir una revisión abierta y adversarial de las medidas que adopta, tiene pocas probabilidades de mantener el equilibrio adecuado entre la seguridad y la libertad. La guerra contra el terrorismo no es solamente un desafío para la democracia; es un cuestionamiento de la vitalidad de su capacidad para la revisión adversarial.

\section{II}

Habiendo establecido los requisitos rudimentarios de un criterio del mal menor en la guerra contra el terrorismo, debo decir algo sobre la palabra mal. En primer lugar, no todo mal es perpetrado por personas malas ni con malos propósitos. Algunas de las peores cosas que se han hecho a los seres humanos se hacen con la mejor intención del mundo. El mal característico de las democracias generalmente es producto de la ceguera de las buenas intenciones. El mal al que me estoy refiriendo 
es el que cometen los funcionarios de los Estados democráticos liberales que saben que no deben hacer el mal, que trabajan para instituciones creadas como protección en contra del mal. Sin embargo, es posible que actúen mal porque creen que estas acciones se justifican para prevenir males mayores o porque, dado el tamaño de las burocracias modernas, apenas conocen las consecuencias de sus acciones.

No obstante, ¿por qué habrían de tener alguna relación las democracias con el mal? ¿Por qué exponer a sus funcionarios a tal peligro moral? ¿Por qué no evitar riesgos permaneciendo del lado de la pura legalidad? La respuesta es que estamos frente a gente mala y que para atajarlos quizás debamos responderles con la misma moneda. En tal caso, ¿cómo evitar que los males menores se conviertan en males mayores?

Permítanme admitir que el proceso mismo de justificar un acto como el menor de dos males es un ejercicio de riesgo moral. Podemos hacerlo legítimamente sólo si realmente sabemos lo que estamos haciendo y no intentamos fingir que el carácter necesario de un acto malvado sirve de excusa para su naturaleza moralmente dudosa. De este modo, el hecho de matar a una persona inocente para salvar a cientos de otros podría ser un mal menor, pero sería de todos modos un acto incorrecto. La ley podría aceptar que opera una circunstancia atenuante de responsabilidad, pero ello no eliminaría la naturaleza criminal del acto. La Corte Suprema de Israel ha dictaminado que un agente del Estado puede invocar la necesidad como defensa, si se le acusa de torturar a una persona; esta excusa podría servir para atenuar la sanción por violar la ley pero no justificaría la tortura misma, que sigue siendo un acto criminal $^{16}$.

No es mi intención minimizar el riesgo moral del hecho de recurrir a medios malvados. A veces podemos predecir este riesgo con precisión, pero, en general, no es posible. El hecho de escoger el mal menor con el fin de evitar un mal mayor quizás no sirva para impedir que igualmente se produzca el mal mayor. Por ejemplo, al intensificar un conflicto militar, un comandante puede optar por aumentar lo menos posible el grado de fuerza utilizado con el fin de mantener al mínimo los daños y lograr un objetivo militar con el menor costo posible. Sin embargo, este enfoque puede hacer que el rival redoble su voluntad de resistir, produciendo con ello el resultado involuntario de un conflicto que cuesta más vidas, posiblemente para ambos lados, que lo que habría ocasionado una escalada corta e intensa ${ }^{17}$. Las consecuencias negativas no son siempre previsibles y, por lo tanto, al escoger la opción del mal menor, posiblemente estemos disparando al azar a sabiendas que, lamentablemente, las buenas intenciones no pueden eximirnos de la responsabilidad cuando se producen consecuencias negativas.

Una razón adicional por la cual el hecho de utilizar el recurso del mal menor conlleva riesgo moral es que los seres humanos son sumamente hábiles para inventar buenas intenciones, ingeniándoselas para desarrollar excusas aceptables en relación con consecuencias
16 Israeli Supreme Court Judgment on the Interrogation Methods Applied by the GSS (6 de septiembre de 1999), http://www.us-israel.org/ jsource/

Society_\&_Culture/

GSS.html (con acceso el 4 de diciembre de 2003):

Además, la defensa basada en la "necesidad" tiene como efecto permitir a quien actúa bajo las circunstancias de la "necesidad" eludir la responsabilidad criminal.

La defensa basada en la

"necesidad" no posee un valor normativo adicional. Asimismo, no autoriza el uso de medios físicos con el fin de permitir a los investigadores ejecutar sus obligaciones en circunstancias de necesidad. El propio hecho de que un acto en particular no constituya un acto criminal (debido a la defensa de que es una "necesidad") no autoriza en sí mismo a la administración a perpetrar este acto y al hacerlo, violar los derechos humanos. [Versión libre del traductor].

17 Michael Ignatieff, Virtual War: Kosovo and Beyond (New York, Metropolitan, 2000), conclusión. 
18 Eurípides, Medea, traducción al inglés de Rex Warner (New York: Dover Publications, 1993), 40. atroces. Eurípides, el dramaturgo de la Grecia antigua, nos proporciona un relato particularmente decidor de esta situación en Medea. Esta obra relata la historia de una mujer que asesina a sus dos hijos con el fin, según ella, de evitarles el horror de ser asesinados por extraños:

Mujeres, es mi tarea matar mis hijos tan pronto como pueda y abandonar esta Tierra, y no, por dejar pasar el tiempo, soportar que mis hijos.

Sean asesinados por otra mano menos bondadosa con ellos.

La fuerza ha determinado que deben morir y

Dado que esto debe ser así, yo, su madre, los mataré ${ }^{18}$.

[versión libre del traductor]

Pero, como ella también quiere vengarse del padre de los niños porque la ha abandonado, no es posible ver a Medea desde un punto de vista moral totalmente incondicional. Quizás les esté ahorrando sufrimiento a sus hijos pero también es dable pensar que los está sacrificando por su propia furia. Incluso llega a confesarlo:

Sé bien el mal que pienso hacer,

Pero más fuerte que todas mis reservas es mi furia,

Una furia que derrama sobre los mortales el más grande de los males.

[versión libre del traductor]

Por otra parte, desde el punto de vista de sus hijos, ¿quién puede decir que ser asesinado por la propia madre es más misericordioso que ser asesinado por extraños? Solamente si tenemos la certeza de que serían torturados, abusados y luego asesinados por extraños podemos justificar su acto como un mal menor. Porque Eurípides es un gran dramaturgo nos deja, en nuestra calidad de público, en la duda acerca de este punto y, por esta razón, dos mil años más tarde, cuando salimos del teatro seguimos preguntándonos si Medea es un monstruo que se justifica a sí misma o un trágico ángel de misericordia.

Tal como nos muestra Eurípides, los seres humanos son capaces de justificar cualquier cosa como un mal menor si tienen que hacerlo solamente frente a sí mismos. En el caso de Medea, el público ve con mayor claridad que la misma Medea, si bien no logra desentrañar sus motivos. En esta obra, el mal aparece como la incapacidad de tomar distancia, a través de la razón, de la fuerza primigenia del sentimiento, de modo que toda la emoción fuerte se vuelve automáticamente autojustificatoria.

El mal también puede presentarse de manera racional, en la forma de una opción cuidadosa y deliberada de hacer daño, motivada por un cálculo racional pero equivocado de un bien anticipado. De cualquier modo, en el dolor histérico o en el cálculo frío, el curso del mal menor puede conducir a la tragedia o al crimen. Pero como insiste Eurípides, estas elecciones son elementos ineludibles de la experiencia humana. Una guerra contra el terrorismo presenta tales opciones a los dirigentes: infligir daño a algunos para salvar a otros, engañar a algunos para tenderle una trampa a otros, matar a algunos para conservar la libertad de otros. La democracia ha sido diseñada para 
enfrentar opciones trágicas y esto lo hace entendiendo que si bien cualquiera puede justificar cualquier cosa, supuesto que lo justifique sólo ante sí mismo, es menos probable que lo lleve a la práctica si se ve obligado a justificarlo en procedimientos adversariales frente a sus conciudadanos.

Sin embargo, esto no significa que los demócratas no cometan actos malvados a veces. Ningún sistema político es capaz de salvarnos del peligro moral. Efectivamente, como lo entendió hace mucho Maquiavelo, las decisiones dudosas no son simples incidentes accidentales en la vida política: forman parte inherente de la acción política. Maquiavelo se hizo famoso por insistir que las cualidades morales que admiramos en la vida privada, a saber la probidad, la honradez, la clemencia, pueden convertirse en desventajas en la vida pública y que el hecho de aplicar los escrúpulos privados a las decisiones que es necesario tomar cuando está en juego la seguridad de la república podría conducir a ésta al desastre $^{19}$. Gracias a Maquiavelo nos resulta conocida la ironía de que un político que en la vida privada condenaría los homicidios, no dudaría en ordenar a sus fuerzas armadas que maten en masa a los enemigos de la república. El mismo líder político que sentiría vergüenza de mentirle a su propia familia, no debería dudar en actuar con doblez frente al poder legislativo cuando la seguridad pública requiere que se mantenga oculta una misión secreta para proteger la república.

Si bien Maquiavelo afirma que toda la vida política necesariamente implica males menores, no se pregunta si la democracia impone límites particulares a los tipos de males que los demócratas pueden considerar. Aunque el derecho internacional fija normas para los Estados, independientemente de si son libres o si son tiranías, bien o mal gobernados, parece evidente que los Estados democráticos se sujetarán a sí mismos a estándares más elevados de dignidad y debido proceso.

Lo hacen así porque los Estados liberales buscan crear un espacio libre para la deliberación democrática y para establecer límites estrictos a los poderes coercitivos del gobierno ${ }^{20}$. Este es el doble sentido en el cual las democracias se oponen a la violencia: en forma positiva, buscan crear instituciones libres en las cuales las políticas públicas son decididas libremente en vez de mediante el temor y la coerción; negativamente, buscan reducir a un mínimo la coacción y la violencia necesarias para mantener el orden entre personas libres.

Esto no rige para otros competidores de la democracia en el siglo veinte. En la Alemania de Hitler o en la Rusia de Stalin, la ley, la política y la cultura estaban organizadas de forma de eliminar la idea misma de que la violencia gubernamental era problemática. Los actos de exterminio de Hitler y Stalin, lejos de ser un mal, eran proclamados como hechos necesarios para la creación de una utopía: un mundo de unidad de clase y justicia social o bien, en el caso del Reich de los Mil Años, una nación depurada de enemigos raciales ${ }^{21}$. Si tales eran las utopías para las que debían servir la lucha de clases y el exterminio
${ }^{19}$ Nicolás Maquiavelo, El Príncipe, traducción al inglés y edición de Robert M. Adams (Nueva York: Norton, 1977), 44-45.

“De aquellas cosas por las cuales los hombres y especialmente los príncipes son alabados o censurados": "No debe preocuparse gran cosa porque se le reproche en razón de vicios sin los cuales difícilmente podría salvar el Estado, porque si consideramos esto con frialdad, hallaremos que, a veces, si sigue lo que parece virtud causaría su ruina, en tanto que lo que parece vicio sólo le traería seguridad y prosperidad". Isaiah Berlin, "The Originality of Machiavelli", en Against the Current (New York: Viking, 1980).

20 Isaiah Berlin "Two Concepts of Liberty" en Four Essays on Liberty (Oxford: Oxford University Press, 1969), 165:

Si yo deseo conservar mi libertad, no es suficiente decir que no debe ser violada a menos que alguna persona, como el gobernante absoluto o la asamblea popular o el rey o el parlamento o los jueces o alguna combinación de autoridades o las leyes mismas (porque las leyes pueden ser opresoras), autoricen su violación. Debo establecer una sociedad en la cual haya ciertas fronteras que nadie debe estar autorizado a traspasar. Se podrán dar diferentes nombres o naturalezas a las reglas que determinen dichas fronteras; podrán denominarse derechos naturales, la palabra de Dios, Derecho Natural, demandas de la utilidad o "los intereses permanentes de la humanidad"; puedo creer que éstos son válidos a priori, o afirmar que constituyen mis propios 
fines últimos o los fines de mi propia sociedad o mi cultura. Lo que tendrán en común estas reglas o mandamientos es que sean aceptados tan ampliamente y arraigados tan profundamente en la verdadera naturaleza de los seres humanos tal como se han desarrollado en el curso de la historia como para que, a estas alturas, constituyan una parte esencial de lo que consideramos un ser humano normal. La creencia genuina en la inviolabilidad de un grado mínimo de libertad individual implica una posición absoluta de esta naturaleza porque está claro que poco se puede esperar del gobierno de las mayorías; la democracia como tal no está lógicamente comprometida con ella, e históricamente en ocasiones no ha cumplido con protegerla aunque haya permanecido fiel a sus propios principios. Se ha observado que pocos gobiernos han enfrentado serias dificultades para lograr que sus súbditos generen la voluntad que el gobierno desea. "El triunfo del despotismo consiste en obligar a los esclavos a declarar que son libres".

Puede no requerirse fuerza alguna, los esclavos pueden proclamar su libertad muy sinceramente, a pesar de lo cual siguen siendo esclavos. Quizás el valor principal que tiene para los liberales los derechos políticos "positivos" de participación en el gobierno es que son un medio para proteger lo que ellos consideran el valor fundamental, a saber el valor de la libertad individual "negativa". [versión libre del traductor]

21 Michael Ignatieff, "Genocide: An Essay", en Simon Norfolk, For Most of It I have No Words (Londres, Dewi Lewis, 1998). racial, la violencia ejercida a su servicio difícilmente podía ser considerada un crimen. En consecuencia, la sola idea de que la violencia puede ser un mal menor sólo tiene sentido en sociedades muy diferentes de las recién descritas.

Gracias a los derechos que encarnan, a las reglas del debido proceso que respetan, a la segregación de poderes que buscan ejercer y al requisito de consentimiento democrático, todas las democracias liberales están guiadas por un compromiso constitucional de minimizar el uso de medios dudosos, a saber la violencia, la fuerza, la coacción, y el engaño, para gobernar a sus ciudadanos. Debido a que operan de este modo en tiempos normales se sienten en la obligación de hacerlo así también en tiempos de emergencia. De lo contrario, estas sociedades no serían fieles a sí mismas. Cuando los ciudadanos consienten a ser gobernados, lo hacen a condición de que la restricción de su libertad, que es necesaria para conservar un dominio público libre y seguro, debe mantenerse al mínimo. Esto significa que en una democracia liberal incluso el gobierno basado en el consentimiento es coercitivo. Dicha coacción abarca desde el cobro de impuestos y la imposición de multas hasta las sanciones de tipo criminal o civil. La coacción puede ser necesaria para mantener el orden social pero en una teoría democrática de gobierno es un mal y debe ser mantenida al mínimo indispensable ${ }^{22}$. De lo contrario, ¿por qué habría una sociedad liberal de asignar tanto valor a los derechos si no buscara proteger a los individuos del ejercicio abusivo del poder coercitivo?

Esta descripción de la democracia liberal puede sonarle extraña a algunas personas porque recalca los poderes coercitivos del gobierno y no hace hincapié en su papel positivo y creador de bienes públicos, tales como escuelas, obras viales, seguridad pública, hospitales y servicios de seguridad social, que permiten que las personas ejerzan su libertad. Estos son bienes positivos, creados gracias al consentimiento de los gobernados. Sin embargo, el consentimiento de la mayoría no elimina el problema de las restricciones impuestas a la minoría. Dichos bienes positivos son pagados mediante una medida represiva, los impuestos, que la mayoría de los ciudadanos, aunque no todos, aceptan en favor del bien mayor. No todos los ciudadanos estarán de acuerdo respecto de qué porción de sus ingresos personales debiera ser objeto de impuestos para financiar esta infraestructura pública ni cuán extensa debiera ser la misma. Las discusiones en torno a este punto constituyen la mayor parte de la política pública y el arbitraje de estas disputas, por medio de la legislación y las elecciones, inevitablemente deja a algunos ciudadanos convencidos de que su libertad ha sido indebidamente restringida. Sencillamente no hay consenso acerca de la magnitud adecuada de los bienes públicos o del poder del gobierno. En los márgenes, la limitación intrínseca al gobierno será considerada, al menos por algunos ciudadanos, como un mal menor ante el cual es necesario someterse como una condición de la vida pública. 
Podría plantearse la pregunta de si los usos coercitivos necesarios del poder del gobierno deben siquiera ser considerados un mal. Puede que los impuestos no sean populares pero difícilmente pueden considerarse un mal. Sin embargo, otros actos del gobierno, como los castigos, que infligen daño en forma directa a las personas, sí hacen pensar en el mal, o al menos así sucede en nuestro tipo de sociedades. Solamente las democracias liberales tienen sentimientos de culpa respecto del castigo. Las sociedades totalitarias han adoptado la coerción con entusiasmo como un instrumento social positivo destinado a crear tipos sociales deseados, trabajadores ideales, ciudadanos obedientes, funcionarios entusiastas del partido. Solamente en las sociedades liberales la gente cree que el dolor y el sufrimiento que implica privar a la gente de su liberad nos debe hacer pensar dos veces antes de imponer esta limitación incluso a aquellos que se lo merecen ${ }^{23}$. El hecho de que sea necesario y justo no lo hace menos doloroso. Es necesario castigar a los criminales, pero el sufrimiento que causa dicho castigo sigue siendo, sin embargo, un mal.

Podría decirse que este ejemplo no logra distinguir entre las acciones necesarias que causan daño y las innecesarias ocasionadas por intenciones aviesas o la negligencia grave. Dicho de otro modo, un mal necesario no puede realmente ser necesario dado que una característica del mal es que no es necesario sino que infundado. Si uno desea seguir manteniendo la idea del mal menor es porque capta la noción, esencial para la teoría liberal, de que la coerción necesaria sigue siendo problemática en términos morales.

Insistir en que el ejercicio justificado de la coerción se puede definir como un mal menor equivale a decir que se puede calificar el mal. Si dos actos son malos, ¿ cómo podemos afirmar que uno es menor y el otro mayor? Calificar el mal de esta manera aparentemente lo disculparía. Sin embargo, es esencial a la idea del mal menor que uno pueda justificar el hecho de recurrir al mal sin negar que es malo, justificable solamente porque otros medios resultarían insuficientes o no estarían disponibles. El propósito de utilizar el término mal en lugar de la palabra daño está orientado a recalcar los elementos de riesgo moral que una teoría liberal de gobierno considera que son intrínsecos al mantenimiento del orden en cualquier sociedad que se basa en la premisa de la dignidad de los individuos.

En consecuencia, incluso en tiempos de seguridad, las democracias liberales buscan limitar el uso de la fuerza necesaria para su conservación. Estos límites intentan equilibrar el conflicto entre los compromisos con la dignidad individual encarnados en los derechos y los compromisos del interés mayoritario encarnados en la soberanía popular. En tiempos de peligro, este conflicto de valores se vuelve intenso. La supresión de las libertades civiles, la vigilancia de las personas, los asesinatos focalizados, la tortura y la guerra preventiva colocan al compromiso liberal con la dignidad en una tensión tan evidente y los daños que entrañan son tan serios que, incluso si tales
22 John Stuart Mill "On Liberty" (1869) en On Liberty, ed. Edward Alexander (Peterborough, Ont.: Broadview Press., 1999), pp. 51-52:

El objeto de este Ensayo es afirmar un sencillo principio destinado a regir absolutamente las relaciones de la sociedad con el individuo en lo que tengan de compulsión o control, ya sean los medios empleados la fuerza física en forma de penalidades legales o la coacción moral de la opinión pública. Este principio consiste en afirmar que el único fin por el cual es justificable que la humanidad, individual o colectivamente, se entrometa en la libertad de acción de uno cualquiera de sus miembros, es la propia protección. Que la única finalidad por la cual el poder puede, con pleno derecho, ser ejercido sobre un miembro de una comunidad civilizada contra su voluntad, es evitar que perjudique a los demás. Su propio bien, físico o moral, no es justificación suficiente. Nadie puede ser obligado justificadamente a realizar o no realizar determinados actos, porque eso fuera mejor para él, porque le haría feliz, porque, en opinión de los demás, hacerlo sería más acertado o más justo. Estas son buenas razones para discutir, razonar y persuadirle, pero no para obligarle o causarle algún perjuicio si obra de manera diferente. Para justificar esto sería preciso pensar que la conducta de la que se trata de disuadirle produciría un perjuicio a algún otro. La única parte de la conducta de cada uno por la que él es responsable ante la sociedad es la que se refiere a los demás. En la parte que le concierne 
meramente a él, su independencia es, de derecho, absoluta. Sobre sí mismo, sobre su propio cuerpo y espíritu, el individuo es soberano. [Traducción tomada de la página de Internet del Movimiento Libertario de Costa Rica] (N. del T.)

23 Véase mi texto A Just Measure of Pain: Penitentiaries in the Industrial Revolution (Nueva York: Pantheon, 1978) donde aparece una discusión sobre las teorías Beccarianas y postBeccarianas acerca del castigo durante la Ilustración europea. medidas son requeridas por razones imperiosas del interés mayoritario, sólo se debe hablar de ellas en el lenguaje del mal.

Sostengo que en una guerra contra el terrorismo el tema no es si podremos evitar por completo los actos malvados, sino si lograremos escoger los males menores e impedir que se conviertan en males mayores. En mi opinión, deberíamos hacerlo asumiendo algunos compromisos iniciales con el principio conservador (conservando las instituciones libres que tenemos), con el principio de dignidad (resguardando a las personas de los daños graves) y luego razonando para determinar las consecuencias de varios cursos de acción, anticipando los daños y llegar así a un juicio racional acerca de cuál curso de acción tiene menos probabilidades de ser menos dañino para los dos principios. Cuando hayamos quedado satisfechos de que una medida represiva es auténticamente el último recurso, justificada por los hechos tal y como podemos entenderlos, habremos escogido el mal menor y tendremos derecho a seguir con esa opción aunque el costo sea más elevado de lo que pensamos inicialmente, aunque no de manera indefinida. En algún momento, cuando lleguemos al punto en que sea necesario "destruir la aldea para salvarla", podremos llegar a la conclusión de que nos hemos deslizado del mal menor al mal mayor. En ese caso no tendremos otra opción que reconocer nuestro error y revertir el curso. En las situaciones de incertidumbre factual en las cuales se deben tomar la mayoría de las decisiones relacionadas con el terrorismo, probablemente sea inevitable el error.

Es tentador suponer que la vida moral puede obviar este "deslizamiento" simplemente evitando los medios malvados por completo. Pero es posible que esta opción angelical sencillamente no exista. O combatimos el mal con el mal o sucumbimos. Así que si recurrimos al mal menor, debemos hacerlo, en primer lugar, plenamente concientes de que el mal está involucrado. En segundo lugar, debemos actuar bajo un estado demostrable de necesidad. En tercer lugar, debemos escoger medios malos solamente como último recurso, una vez que hayamos intentado todo lo demás. Por último, debemos cumplir con una cuarta obligación: debemos justificar públicamente nuestras acciones frente a nuestros conciudadanos y someternos a su juicio en cuanto a su corrección.

III

El desafío de evaluar cuáles medidas podrían ser lícitas consiste en encontrar una posición viable entre el cinismo y el perfeccionismo. El cinismo afirmaría que una reflexión ética es irrelevante: los agentes del Estado harán lo suyo y lo mismo harán los terroristas, y solamente la fuerza y el poder determinarán el resultado. La única pregunta que cabe formular respecto de estos medios es si funcionan. Los cínicos están equivocados. Todas las batallas entre los terroristas y el Estado son batallas de opinión y, en esta lucha, las justificaciones éticas son cruciales para resguardar la moral de los propios partidarios, para 
conservar la lealtad de las poblaciones que, de lo contrario, podrían alinearse con los terroristas y para mantener el apoyo político entre los aliados. Probablemente una campaña antiterrorista podría ser manejada solamente por cínicos, por profesionales entrenados en el manejo de las apariencias morales, pero incluso los cínicos saben que es necesario cumplir algunas promesas morales para tener credibilidad. La detención preventiva para sacar a los extranjeros sospechosos de la población puede desbaratar las redes terroristas pero puede producir tanta ira entre grupos inocentes que éstos dejarían de cooperar con la policía. La tortura podría despedazar una red de células terroristas pero también generaría odio y resentimiento entre los sobrevivientes de la tortura e incrementaría su apoyo entre la población descontenta. Simplemente no hay manera de separar la cuestión técnica de qué es lo que funciona, de la cuestión política de qué impacto tendrán tales métodos en la lucha por la opinión, lo cual es la esencia de cualquier campaña en contra del terrorismo. Con medidas extremas, tales como la tortura, la detención preventiva y el arresto arbitrario, generalmente se gana la batalla pero se pierde la guerra. Incluso los cínicos saben que las victorias pírricas son más que inútiles.

En cuanto al perfeccionismo moral, esta sería la doctrina que un Estado liberal nunca debería involucrarse con medios de dudosa moralidad y debiera salvaguardar a sus funcionarios del peligro de tener que decidir entre males menores y males mayores. Una posición de perfeccionismo moral también sostiene que los Estados pueden proteger a sus funcionarios de este peligro simplemente si adhieren a las normas morales establecidas en las convenciones de derechos humanos y las leyes de la guerra.

Hay dos problemas con la postura perfeccionista, sin considerar siquiera si es un tema realista. El primer punto es que articular estándares morales irrevocables, no derogables, es relativamente fácil. El problema radica en decidir cómo aplicarlos en casos específicos. ¿Dónde está el límite entre la interrogación y la tortura, entre el homicidio focalizado (targeted killing) y el asesinato ilegal, entre la prevención y la agresión? Incluso cuando las distinciones legales y morales entre estos aspectos quedan claras en abstracto, las abstracciones son bastante poco útiles cuando los líderes políticos tienen que escoger entre ellas en la práctica. Además, el problema con los estándares perfeccionistas es que son contradictorios entre sí. La misma persona que se estremece, correctamente, ante la perspectiva de torturar a un sospechoso, podría estar dispuesta a asesinar al mismo sospechoso en un ataque preventivo contra una base terrorista. Asimismo, el compromiso perfeccionista al derecho a la vida podría excluir estos ataques por completo y limitar la respuesta a perseguir judicialmente a los ofensores a través de procesos legales. Las respuestas judiciales al problema del terrorismo tienen su función, pero no son un substituto de las operaciones militares cuando los terroristas poseen bases, campos de entrenamiento y armamento 
24 Hannah Arendt, "Personal Responsibility under Dictatorship", en Responsibility and Judgment, ed. Jerome Kohn (Nueva York: Schocken Books, 2003), 44. pesado. Adherir a un compromiso perfeccionista al derecho a la vida ante un ataque terrorista puede lograr la coherencia moral a costa de dejarnos en la indefensión ante los malhechores. Además, la seguridad es un derecho humano y el respeto por un derecho podría llevarnos a traicionar otro derecho.

Una moralidad del mal menor es antiperfeccionista en sus supuestos. Acepta como inevitable que no siempre es posible salvar a los seres humanos del daño sin matar a otros seres humanos; no siempre es posible conservar la plena revelación y transparencia democráticas en las operaciones antiterroristas; no siempre es deseable que los líderes democráticos eviten el engaño y la deslealtad; no siempre es posible preservar la libertad de la mayoría sin suspender las libertades de una minoría; no siempre es posible prever que acciones bien intencionadas tengan consecuencias terribles, etc. Lejos de hacer que la reflexión ética sea irrelevante, estos dilemas hacen que el realismo ético sea mucho más esencial para la reflexión democrática y las buenas políticas públicas. El hecho de que líderes democráticos liberales puedan ordenar que se mate subrepticiamente a terroristas, puedan ocultar información a su electorado, puedan ordenar la suspensión de las libertades civiles, no necesariamente significa que "todo vale". Incluso si las libertades deben ser suspendidas, este hecho puede ser temporal; si miembros del poder ejecutivo deben ocultar información del poder legislativo en público, pueden estar obligados a revelarlo en una sesión privada o posteriormente. La desinformación pública, cuyo único propósito es engañar al enemigo, puede ser justificada pero nunca es justificable engañar deliberadamente a un electorado democrático con el fin de exagerar el riesgo o minimizar el peligro. Es necesario observar el mismo acto de equilibrismo en otros casos. Si dar muerte focalizadamente a terroristas resulta necesario, puede ser limitado por reglas estrictas de procedimiento y sometido a fiscalización y supervisión por parte del poder legislativo. El interrogatorio de terroristas sospechosos puede realizarse sin recurrir a la tortura. Trazar estos límites significa mantener en vista claramente la cuestión de si estos medios refuerzan o traicionan la identidad democrática que se supone deben defender.

Evitar que los males menores se conviertan en males mayores es más que un asunto de responsabilidad democrática. También es cuestión de conciencia individual. Hannah Arendt argumentó en una ocasión que ser capaz de pensar por sí mismo es un requisito para evitar el mal, especialmente en las grandes burocracias en las cuales se premia la falta de pensamiento independiente. Afirmó que el único común denominador que unía a los opositores al régimen Nazi en Alemania era la capacidad de preguntarse, en todo momento, qué tipo de persona era uno o deseaba ser. Aquellos que se negaban a matar a otros, decía Arendt, "rehusaban asesinar no tanto porque todavía respetaban el mandamiento "No matarás" sino porque no estaban dispuestos a convivir con un asesino, esto es, ellos mismos" ${ }^{24}$. 
Ninguna sociedad puede evitar los crímenes oficiales y la brutalidad a menos que este sentido de responsabilidad sea compartido ampliamente por los funcionarios públicos. Las reglas y los procedimientos no bastan. El carácter es decisivo y hay razones para pensar que las democracias estimulan el tipo correcto de carácter. A la gente que se cría en sociedades que tienen derechos constitucionales se les enseña a creer que sus opiniones son importantes, que tienen derecho a cierta justicia y al debido proceso en los trámites oficiales y que tienen responsabilidad frente a los derechos de los demás. Pero no podemos estar seguros que la democracia nos enseña a todos a hacer lo correcto.

Por otra parte, independientemente de cuán adecuado haya sido nuestro aprendizaje moral, todos necesitamos la fiscalización de parte de buenas instituciones. Una guerra contra el terrorismo pone en tensión a las instituciones. No siempre es posible someter a los agentes de inteligencia y Fuerzas Especiales a una plena fiscalización y control. Sin embargo, los agentes mismos son ciudadanos y su responsabilidad ante el orden constitucional que defienden sigue siendo el tribunal de último recurso que los salvará a ellos y a nosotros de caer en la barbarie. Para saber sobre abusos de poder, dependemos en gran parte de quienes denuncian situaciones irregulares, funcionarios honrados que no pudieron tolerar lo que se les pidió que hicieran ${ }^{25}$. Cualquier democracia que desee llevar a cabo una guerra limpia contra el terrorismo necesita proteger los derechos de estos denunciantes en las agencias más secretas del gobierno, para que cuenten la verdad a los funcionarios electos por voluntad popular y a los medios de comunicación. La única manera de evitar que se generen zonas de impunidad en nuestro gobierno es que los poderes legislativos insistan en su derecho de supervisión, que los medios de comunicación sigan exigiendo su derecho a tener acceso y que la ley respalde el derecho de los denunciantes a contar la verdad.

Pero estos no son los únicos contrapesos morales en una guerra contra el terrorismo. Los instrumentos de derechos humanos, ratificados internacionalmente, junto con la Carta de las Naciones Unidas y las Convenciones de Ginebra, amplían el público ante quien debe formularse una justificación, más allá del electorado de los Estados democráticos que se encuentran bajo ataque directo, extendiéndolo a una red más amplia de Estados y entidades internacionales, cuyos puntos de vista deben ser tomados en consideración. Sus opiniones importan porque las democracias liberales constituyen tanto una comunidad de valores como también una comunidad de intereses, y la acción conjunta y exitosa contra el terrorismo pronto se volvería imposible si los Estados hacen caso omiso de sus aliados, no toman en cuenta sus objeciones frente a las políticas nacionales y buscan obtener ventajas unilaterales o eximirse de sus compromisos internacionales ${ }^{26}$.
25 Daniel Ellsberg, Secrets: $A$ Memoir of Vietnam and the Pentagon Papers (Nueva York: Viking, 2002). Para informarse sobre la carrera de un denunciante en la CIA, véase Robert Baer, See No Evil: The True Story of a Ground Soldier in the CIA's War on Terrorism (Nueva York: Crown Publishers, 2002).

26 Véase Michael Ignatieff, ed., American Exceptionalism and Human Rights (Princeton: Princeton University Press, 2004). 
Las normas internacionales importan pero no debemos suponer que las naciones siempre están de acuerdo en cuanto a su significado. Los países europeos no concuerdan con Estados Unidos acerca de la legitimidad de la pena de muerte y se han negado a extraditar a sospechosos de terrorismo a EE.UU., país en el cual podría imponérseles la pena capital. Las convenciones internacionales prohíben la tortura pero el punto preciso en el que un interrogatorio intenso traspasa la línea roja y se convierte en tortura es debatible. Las Convenciones de Ginebra protegen la idea de la inmunidad de los civiles, pero quiénes deben ser considerados civiles sigue siendo materia de controversia. Las convenciones internacionales fijan las normas pero cada país puede interpretarlas de manera diferente. La forma en que lo hacen los dirigentes políticos depende de lo que parecen permitir los electorados locales. Pero un estándar político no necesariamente equivale a una ética relativista o carente de normas. La opinión pública simplemente no está dispuesta a aceptar cualquier cosa. Las normas que rigen en una guerra contra el terrorismo no son monopolio del gobierno. Son susceptibles de influencia por parte de un activismo moral. Los activistas de derechos humanos y los integrantes de ONG partidarias de las libertades civiles buscarán alzar la vara de lo que es moralmente permisible mientras que los grupos que representan a los militares y la policía pueden desear bajarla. En una democracia liberal, los estándares de una guerra contra el terrorismo serán determinados por la competencia moral adversarial.

Como contribución a este proceso de fijación de los estándares, deseo proponer las siguientes pruebas para los encargados de la formulación de políticas. En primer lugar, una guerra democrática contra el terrorismo necesita someter a todas las medidas de coacción a la prueba de la dignidad: ¿violan la dignidad individual? Los compromisos fundacionales con los derechos humanos siempre deberían excluir la posibilidad del castigo cruel e inusual, la tortura, las penas de trabajos forzados y las ejecuciones extrajudiciales, como también la entrega de los sospechosos a países en los que se cometen abusos contra los derechos humanos. En segundo lugar, las medidas de coacción deben pasar la prueba conservadora: ¿es realmente necesario apartarse de las normas del debido proceso? ¿Le hacen daño a nuestra herencia institucional? Dicha norma eliminaría la posibilidad de la suspensión indefinida del habeas corpus y exigiría que cualquier detención, ya fuera por autoridades militares o civiles, fuera objeto de revisión judicial. Los que han sido privados de sus derechos, tanto los ciudadanos como los que no lo son, jamás deben perder su derecho a tener acceso a un abogado. Una tercera evaluación de las medidas antiterroristas debería ser consecuencialista. ¿Servirán para incrementar la seguridad de los ciudadanos a largo plazo? Esta prueba de la eficacia debe enfocarse no solamente en el corto plazo sino también en las implicaciones políticas de largo plazo que tendrán las medidas. ¿Fortalecerán o debilitarán el apoyo político de aquel Estado que adopte tales medidas? Una consideración adicional es la prueba del último recurso: ¿se han probado medidas 
menos represivas que no han dado resultado? Otro tema importante es si las medidas han pasado la prueba del examen abierto y adversarial por parte de entidades legislativas y judiciales, ya sea en su momento o en cuanto lo permita la necesidad. Por último, "el respeto decente por las opiniones de la humanidad" junto con una necesidad más pragmática de obtener el apoyo de otras naciones en una guerra global contra el terrorismo requiere que cualquier Estado que combate el terrorismo respete sus obligaciones internacionales como también las opiniones ponderadas de sus aliados y amigos. Si todo esto da por resultado una serie de limitaciones que dejan atados de manos a nuestros gobiernos, así sea. Es parte de la naturaleza misma de la democracia que ésta no solamente lucha con una mano atada a la espalda sino que es su deber hacerlo así. También es parte de la naturaleza de la democracia que prevalezca frente a sus enemigos precisamente porque procede de esta manera. 
